Z. Klin. Chem. Klin. Biochem.

11. Jg. 1973 , S. $411-414$

\title{
Kreatininbestimmung im Serum ohne Enteiweißung
}

\author{
Von E. KNoll und H. WISSER \\ Abteilung für Klinische Cbemie des Robert-Bosch-Krankenbauses, Stuttgart
}

(Eingegangen am 28. Juni 1973)

\begin{abstract}
Ein Verfahren zur Kreatininbestimmung im Serum ohne Enteiweißung wurde modifiziert und auf das Mikrolitersystem Eppendorf adaptiert. Der Einfluß von 12 JAFFÉ-positiven Substanzen wurde untersucht. Keine dieser Verbindungen stört die Kreatininbestimmung. Ein Methodenvergleich mit dem Verfahren von Knoll und Stam (1970) diese Z. 8, 582-587 ergab völlige Úbereinstimmung, so dal3 die Normalwerte dieses Verfahrens übernommen werden konnten. Der Wegfall des Enteiweißungsschrittes erlaubt eine Reduzierung des Probenvolumens auf $100 \mu \mathrm{l}$ und bedeutet eine wesentliche Vereinfachung im Vergleich zur früher publizierten Methode (s. o.), wobei aber alle Vorteile dieser Methode - wie Spezifität und Zuverlässigkeit - erhalten bleiben.
\end{abstract}

\section{Determination of creatinine in serum without deproteinization}

A method for the determination of serum creatinine without deproteinization was modified and adapted to the microlitre Eppendorf system. The influence of 12 JAFFE-positive substances was investigated, and none of these was found to interfere in the creatinine determination. The present method gave identical results to those obtained by the method of KNoll and STAMM (1970) this j. 8, $582-587$ so that normal values from the latter method could be used. Omission of the deproteinization step permits a reduction of the sample volume to $100 \mu 1$, and represents an essential simplification compared with the earlier published method, while retaining all its advantages, such as specificity and reliability.

Zur Bestimmung des Kreatinins im Serum gibt es verschiedene Methoden. Als Routinebestimmung wird am häufigsten die JAFFÉ-Reaktion benutzt. Eines der Hauptprobleme dieses Verfahrens ist die Frage der Spezifität. Verschiedene Nichtkreatininchromogene reagieren nämlich ebenfalls mit alkalischer Pikratlösung. Wie von anderer Seite $(1,2)$ gezeigt werden konnte, ist die Störung durch Nichtkreatininchromogene nicht proportional der Kreatininkonzentration, sondern additiv. Im Normalbereich führt sie zu einer positiven Fehlbestimmung von $15-20 \%(1,2)$. Da der Störeinfluß aber nur additiv ist, ist er bei hohen Kreatininkonzentrationen praktisch vernachlässigbar. Er macht sich nur im Normalbereich bzw. im Grenzbereich normal/pathologisch störend bemerkbar.

Dieser Störeinfluß kann auf verschiedene Weise beseitigt werden. In jüngster Zeit sind mehrere Arbeiten erschienen, die durch Berücksichtigung der unterschiedlichen Reaktionsgeschwindigkeiten von Kreatinin und Nichtkreatininchromogenen mit alkalischer Pikratlösung den Störeinfluß der Letzteren weitgehend ausschalten $(3,4,5,6,7,8,9)$. Dieses Verfahren erfordert allerdings eine genaue zeitliche Abfolge von Reagenzienzugabe und photometrischer Messung, was am zuverlässigsten durch eine mechanisierte Meßanordnung bewerkstelligt wird. Vorteilhaft bei dieser Methode ist der Wegfall des Enteiweißungsschrittes. Wird die kinetische Bestimmung manuell durchgeführt, so sind genaues „timing“ und zweimalige photometrische Messung hinderlich. Ein weiteres Verfahren zur Elimination des Störeinflusses der Nichtkreatininchromo- gene benutzt die pH-Abhängigkeit der KreatininPikratreaktion (10). Diese Methode, die ebenfalls ohne Enteiweißung arbeitet, vermeidet die Störung durch Eiweiß und andere Substanzen (bei starker Erhöhung) nicht vollständig. Andere Verfahren werden als zu aufwendig für die Routine angesehen. Bei diesen wird das Kreatinin durch Ausschütteln seines Tetraphenylborats mit Diäthyläther bei $\mathrm{pH} 2,5(1,2)$, durch Ionenaustauscher $(11,12,13,14)$ oder durch Adsorption an Fullererde $(15,16,17)$ von den Störsubstanzen abgetrennt. Durch Reduzierung der Probenmenge und Modifizierung einiger Reaktionsschritte konnte ein Teil dieser Nachteile für das „Fullererdeverfahren" beseitigt werden (18). Nachteilig bei dem letzteren Verfahren sind die zahlreichen Pipettierschritte, die immer noch relativ̀ große Probenmenge und der Enteiweißungsschritt. Eine Vereinfachung der Kreatininbestimmung bei Verringerung der Probenmenge und den Vorteilen der Spezifität durch Adsorption an Fullererde erschien somit wünschenswert. Aus diesem Grunde wurde eine Kreatininbestimmung ohne Enteiweißung mit Adsorption an Fullererde (19) modifiziert, auf das Mikrolitersystem Eppendorf adaptiert und mit der Methode von KNoll und Stamm (18) verglichen.

\section{Methodik}

Kreatinin wird durch Adsorption an Fullererde ohne Enteiweißung aus dem Serum abgetrennt. Dic Fullererde wird mit Wasser gewaschen und anschließ3end das Kreatinin mit der JAFré-Reaktion bestimmt. 


\section{Geräte}

1. Eppendorf Mikrolytersystem $3000^{1}$ ), einschließlich MarburgPipetten, Mikrozentrifugen, Rüttler zum Mischen, Mikromix mit Platinrührer.

2. MT-2 Küvetten, $d=2 \mathrm{~cm}^{2}$ ).

3. Eppendorf-Photometer mit Cadmium-Lampe und Filter $509 \mathrm{~nm}^{1}$ ) oder Spektralphotometer $\mathrm{PM}-4^{2}$ ).

\section{Reagenzien und Lösungen}

Wenn nicht besonders vermerkt, wurden p. a. Reagenzien der Firma Merck, Darmstadt benutzt.

1. Fullererde $\left.{ }^{3}\right)$-Suspension: $3 \mathrm{~g}$ Fullererde in $50 \mathrm{ml} \mathrm{HCl}(0,4 \mathrm{~mol} / \mathrm{l})$ suspendiert.

2. $\mathrm{MgCl}_{2}$-Lösung, 0,15 mol/1: 3,06 $\mathrm{g} \mathrm{MgCl}_{2} \cdot 6 \mathrm{H}_{2} \mathrm{O} / 100 \mathrm{ml}$ dest. Wasser.

3. Pikrinsäurelösung, $52,4 \mathrm{mmol} / 1$.

4. $\mathrm{NaOH}, 1,6 \mathrm{~mol} / \mathrm{l}$.

5. Gemisch von Lösung 3 und 4: $32 \mathrm{ml}$ Lösung 3 und $10 \mathrm{ml}$ Lösung 4 werden mit dest. Wasser auf $100 \mathrm{ml}$ aufgefüllt und in dunkler Flasche bei $4^{\circ} \mathrm{C}$ aufbewahrt $t^{4}$ ).

6. Kreatininstandard:

Stammlösung: $113,12 \mathrm{mg} / 100 \mathrm{ml}$ Kreatinin in $\mathrm{HCl}(0,1 \mathrm{~mol} / \mathrm{l})$. Arbeitslösung: 1:100 Verdünnung der Stammlösung mit destilliertem Wasser (=100 $\mu \mathrm{mol} / 1 \mathrm{Kreatinin})$.

\section{Arbeitsweise}

$100 \mu 1$ Serum (P), $100 \mu \mathrm{l}$ Arbeitslösung des Standards (St) bzw. $100 \mu \mathrm{l}$ destilliertes, Wasser (L) werden in Eppendorf-Reaktionsgefäßen mit $50 \mu \mathrm{l}$ Fullererde-Suspension versetzt und fünf Minuten geschüttelt. Nach Zugabe von $1 \mathrm{ml}$ destilliertem Wasser wird eine weitere Minute geschüttelt. Anschließend wird die Fullererde abzentrifugiert $(1-2 \mathrm{~min})$ und der Überstand verworfen. $\mathrm{Zu}$ der abzentrifugierten Fullererde gibt man $200 \mu \mathrm{l}$ der Magnesiumchloridlösung und wirbelt den Niederschlag mit dem Mikromix auf. Nach anschließender Zugabe von $1 \mathrm{ml}$ der alkalischen Pikratlösung wird 5 min geschüttelt und anschließend die Fullererde abzentrifugiert $(1 \mathrm{~min})$. Die Extinktion des Uberstandes von Standard und Probe wird dann bei 509 nm gegen den Leerwert gemessen.

$$
\begin{aligned}
& \text { Berechnung } \\
& c_{P}=\frac{E_{P}}{E_{S t}} \cdot c_{S t} \\
& E=\text { Extinktion } \\
& c=\text { Konzentration }(\mu \mathrm{mol} / \mathrm{l}) \\
& \mathrm{P}=\text { Probe } \\
& \mathrm{St}=\text { Standard. }
\end{aligned}
$$

\section{Zuverlässigkeitskriterien der Methode}

\section{Präzision}

Für die Streuung in der Serie, ermittelt aus einer Zwölffachbestimmung eines Poolserums, betrug der Variationskoeffizient $1,3 \%(\overline{\mathrm{x}}=88 \mu \mathrm{mol} / \mathrm{l}, \mathrm{s}=1,12 \mu \mathrm{mol} / \mathrm{l})$.

\section{Richtigkeit}

Die Richtigkeit wurde durch Aufstockversuche überprüft. Die Wiederfindung betrug bei einem Aufstockungszusatz von:

$8,84 \mathrm{nmol} / 0,1 \mathrm{ml}$ Serum - $99 \%$

$17,68 \mathrm{nmol} / 0,1 \mathrm{ml}$ Serum $-103,5 \%$

$26,52 \mathrm{nmol} / 0,1 \mathrm{ml}$ Serum $-100 \%$.

\footnotetext{
1) Eppendorf-Gerätebau, Netheler \& Hinz GmbH, Hamburg.

2) Firma Carl Zeiss, Oberkochen/Württemberg.

3) Serva Entwicklungslabor, Heidelberg.

4) Die Extinktion der so aufbewahrten alkalischen Pikratlösung steigt zwar im Verlauf von 14 Tagen um etwa $20 \%$ an (gemessen gegen Wasser bei $509 \mathrm{~nm}$ ), doch sind die damit ermittelten Kreatininkonzentrationen eines Poolserums im gleichen Zeitraum konstant.
}

Die angegebenen Werte für die Wiederfindung sind Mittelwerte aus Dreifachbestimmungen. Der Einfluß von Störsubstanzen wird im Abschnitt Ergebnisse und Diskussion besprochen.

Nachweisgrenze

Die Nachweisgrenze, berechnet aus der dreifachen Standardabweichung der Streuung in der Serie $(n=12)$ der Reagenzienleerwerte liegt bei $3 \mu \mathrm{mol} / 1$.

\section{Ergebnisse und Diskussion}

Bis zu einer gemessenen Konzentration von $1768 \mu \mathrm{mol} / 1$ Kreatinin (=20 mg $/ 100 \mathrm{ml}$ Kreatinin) wurde eine lineare Abhängigkeit von Extinktion und Kreatininkonzentration gefunden.

Wie in einer vorhergehenden Arbeit gezeigt werden konnte, ist die Adsorption des Kreatinins an Fullererde unvollständig. Durchschnittlich blieben $7-8 \%$ des Kreatinins in Lösung. Der gleiche „Fehlbetrag“ wurde mit der hier beschriebenen Methode bei der Analyse einer wäßrigen Lösung ( $88 \mu \mathrm{mol} / 1$ Kreatinin) ermittelt. Um diesen Fehler auszugleichen, wird der Standard durch den gesamten Analysengang mitgeführt.

Nach unseren Versuchen besteht kein Unterschied zwischen einem Reagenzienleerwert, der analog dem Standard bzw. der Probe behandelt wird und einer alkalischen Pikratlösung nach Zusatz der Magnesiumchloridlösung. Aus praktischen Erwägungen wird in der oben angegebenen Arbeitsvorschrift der Leerwert ebenfalls durch den gesamten Analysengang mitgeführt. Bei den Kreatininbestimmungen ohne vorhergehende Abtrennung des Kreatinins zeigt die Extinktion des Reaktionsgemisches eine starke Abhängigkeit von der Zeit; so kommt es über einen Zeitraum von $60 \mathrm{~min}$ zu einer stetigen Zunahme der Extinktion, während nach Abtrennung des Kreatinins mit Fullererde die Farbstoffentwicklung nach $20 \mathrm{~min}$ abgeschlossen ist und dann nur noch geringfügig ansteigt (18). Für die hier beschriebene Modifikation gibt die folgende Abbildung 1 die Zeitabhängigkeit der Farbstoffentwicklüng. wieder.

Nach diesen Versuchen ist der gebildete Farbstoff über einen Zeitraum von $90 \mathrm{~min}$ stabil. Dies bedeutet; daß

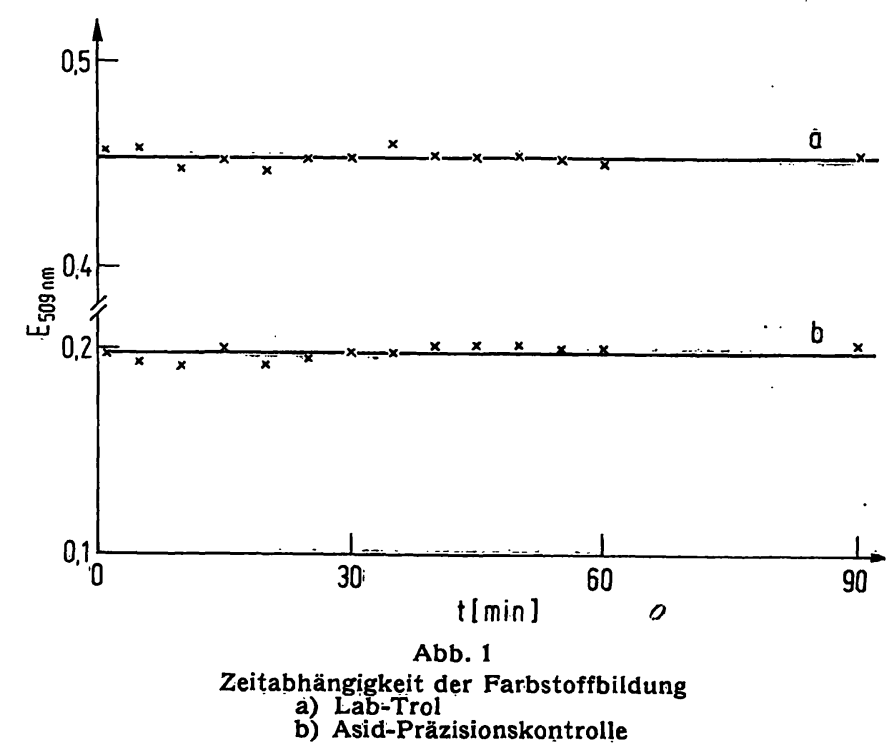


eine größere Anzahl von Proben hintereinander gemessen werden kann, ohne daß es zu einer Fehlbestimmung bei Nichteinhaltung einer genauen zeitlichen Abfolge von Reagenzienzugabe und Meßvorgang kommt.

\section{Spezifität der Methode}

Von den in den folgenden beiden Tabellen 1 und 2 aufgeführten Substanzen ist bekannt, $\mathrm{da} B$ sie eine positive JAFFÉ-Reaktion geben.

Zur Prüfung des Störeinflusses wurden verschiedene Serumproben mit den in den beiden Tabellen angegebenen Störsubstanzkonzentrationen aufgestockt und danach wurde das Kreatinin nach 2 leicht modifizierten Verfahren bestimmt:

Tab. 1

Einfluß von Störsubstanzen auf die Kreatininbestimmung mit und ohne Waschen der Fullererde mit Salzsäure (2 mol/1). Die angegebenen Werte sind Mittelwerte aus Dreifachbestimmungen

\begin{tabular}{|c|c|c|c|}
\hline \multirow[t]{2}{*}{ Störsubstanz } & \multirow[t]{2}{*}{$\begin{array}{l}\text { Zugabe } \\
(\mathrm{mmol} / \mathrm{l})\end{array}$} & \multicolumn{2}{|c|}{$\begin{array}{l}\text { Kreatininkonzentration } \\
\qquad(\mu \mathrm{mol} / 1)\end{array}$} \\
\hline & & $\begin{array}{c}\text { mit } \\
\text { Salzsäure- } \\
\text { waschen }\end{array}$ & $\begin{array}{c}\text { ohne } \\
\text { Salzsäure- } \\
\text { waschen }\end{array}$ \\
\hline \multirow{4}{*}{ Aceton } & - & 63 & 59 \\
\hline & 0,17 & 61 & 59 \\
\hline & 0,86 & 62 & 58 \\
\hline & 1,72 & 63 & 59 \\
\hline \multirow{4}{*}{ Ascorbinsäure } & - & 56 & 55 \\
\hline & 0,07 & 56 & 55 \\
\hline & 0,28 & 54 & 56 \\
\hline & 0,57 & 56 & 56 \\
\hline \multirow{4}{*}{$\begin{array}{l}\text { Natrium- } \\
\text { pyruvat }\end{array}$} & - & 61 & 61 \\
\hline & 0,09 & 60 & 60 \\
\hline & 0,46 & 61 & 61 \\
\hline & 0,91 & 61 & 60 \\
\hline \multirow{4}{*}{ Fructose } & - & 60 & 60 \\
\hline & 0,28 & 60 & 59 \\
\hline & $\cdot 0,56$ & 61 & 60 \\
\hline & 1,39 & 59 & 61 \\
\hline \multirow{4}{*}{ Glucose } & - & 62 & 60 \\
\hline & 11 & 61 & 59 \\
\hline & 55 & 60 & 58 \\
\hline & 110 & 65 & 58 \\
\hline \multirow{4}{*}{$\begin{array}{l}\text { Aminohippur- } \\
\text { säure }\end{array}$} & - & 61 & 61 \\
\hline & 0,05 & 61 & 64 \\
\hline & 0,25 & 61 & 61 \\
\hline & 0,50 & 62 & 61 \\
\hline \multirow{4}{*}{$\begin{array}{l}\text { 2-Oxoglutar- } \\
\text { säure }\end{array}$} & - & 62 & 62 \\
\hline & 0,07 & 62 & 63 \\
\hline & 0,35 & 63 & 63 \\
\hline & 0,70 & 61 & 62 \\
\hline \multirow{4}{*}{ Hydantoin } & - & 65 & 64 \\
\hline & 0,10 & 63 & 62 \\
\hline & 0,50 & 65 & 64 \\
\hline & 1,00 & 65 & 64 \\
\hline \multirow{4}{*}{ Harnsäure } & - & 62 & 65 \\
\hline & 0,36 & 62 & 65 \\
\hline & 0,72 & 63 & 64 \\
\hline & 1,43 & 63 & 65 \\
\hline
\end{tabular}

a) nach der oben angegebenen Vorschrift

b) nach dem Waschen der Fullererde mit $1000 \mu 1$ Wasser wurde zusätzlich noch mit $1000 \mu \mathrm{l}$ Salzsäure $(2 \mathrm{~mol} / \mathrm{l})$ gewaschen.

Nach den Ergebnissen dieser Untersuchungen stört keine der getesteten Verbindungen. Dies gilt sowohl für das Vorgehen mit als auch ohne Waschen der Fullererde mit Salzsäure, d. h. daß die untersuchten Substanzen überhaupt nicht oder in nicht störender Menge von der Fullererde adsorbiert werden.

In der Originalvorschrift (19) wird darauf hingewiesen, $\mathrm{da} B$ Bilirubin in hohen Konzentrationen $\mathrm{zu}$ hohe Kreatininwerte ergibt; in diesem Fall sei eine vorhergehende Enteiweißung notwendig. Dieser Befund wurde von uns durch Analyse eines Kontrollserums mit und ohne Aufstockzusatz von Bilirubin nachuntersucht. Zusätzlich wurde der Einfluß der Hämolyse geprüft, indem das Kreatinin in drei verschiedenen Plasmaproben vor und nach mechanisch erzeugter Hämolyse ${ }^{5}$ ) bestimmt wurde. In der folgenden Tabelle 2 ist das Ergebnis dieser Untersuchungen wiedergegeben.

Sowohl geringgradige Hämolyse wie Bilirubin haben nach diesen Ergebnissen keinen Einfluß auf die Kreatininbestimmung.

Wie von anderen Untersuchern gezeigt werden konnte, stört Eiweiß die Kreatininbestimmung mit alkalischem Pikrat (10). Da das hier beschriebene Verfahren ohne Enteiweißung arbeitet, war ein eventueller Störeinfluß in Erwägung zu ziehen. In einer ersten Versuchsreihe (Tab. 3) wurde ein Poolserum mit einer hohen Kreatininkonzentration unverdünnt und in verschiedenen Verdünnungen analysiert.

Tab. 2

Störeinfluß von Bilirubin und Hämoglobin auf die Kreatininbestimmung. Die angegebenen Werte sind Mittelwerte aus Dreifachbestimmungen

\begin{tabular}{lcl}
\hline \multicolumn{1}{c}{ Substanz } & Konzentration & Kreatinin \\
\hline \multirow{3}{*}{ Bilirubin } & $17, \overline{\mu \mathrm{mol} / 1}$ & $57 \mu \mathrm{mol} / 1$ \\
& $85,5 \mu \mathrm{mol} / 1$ & $55 \mu \mathrm{mol} / 1$ \\
& $171 \mu \mathrm{mol} / 1$ & $57 \mu \mathrm{mol} / 1$ \\
Hämoglobin & - & $57 \mu \mathrm{mol} / 1$ \\
& $2,8 \mathrm{~g} / 1$ & $59 \mu \mathrm{mol} / 1$ \\
& $3,2 \overline{\mathrm{g} / 1}$ & $58 \mu \mathrm{mol} / 1$ \\
& $3,5 \mathrm{~g} / \mathrm{l}$ & $55 \mu \mathrm{mol} / 1$ \\
& & $54 \mu \mathrm{mol} / 1$ \\
\hline
\end{tabular}

Tab. 3

Kreatininkonzentration einer Poolserumprobe unverdünnt und verdünnt analysiert. Die angegebenen Werte sind Mittelwerte aus Doppelbestimmungen

\begin{tabular}{lcccc}
\hline Probe & Serum & $\begin{array}{c}\text { Serum } \\
1: 2 \\
\text { verdünnt }\end{array}$ & $\begin{array}{c}\text { Serum } \\
1: 4 \\
\text { verdünnt }\end{array}$ & $\begin{array}{c}\text { Serum } \\
1: 8 \\
\text { verdünnt }\end{array}$ \\
\hline $\begin{array}{l}\text { Kreatinin } \\
(\mu \text { mol/l) }\end{array}$ & 612 & 605 & 621 & 615 \\
\hline$\ldots$ & $\cdots$
\end{tabular}

5) Hämoresistometer nach FrLiscir, Firma Métabo, Epalinges (Schweiz). 
Tab. 4

Kreatininkonzentration einer wäßrigen Lösung mit steigender Albuminkonzentration. Die angegebenen Werte sind Mittelwerte aus Dreifachbestimmungen

\begin{tabular}{lcccc}
\hline $\begin{array}{l}\text { Albumin }(g / 1) \\
\begin{array}{l}\text { Kreatinin } \\
(\mu \mathrm{mol} / \mathrm{l})\end{array}\end{array}$ & 0 & 20 & 40 & 80 \\
\hline
\end{tabular}

Es zeigt sich, daß die ermittelte Kreatininkonzentration unabhängig von der Serumverdünnung ist. Dieser Versuch ist allerdings noch nicht beweisend; denn es könnte ein konstanter Anteil des Eiweißes an Fullererde adsorbiert werden, der in einem größerem Konzentrationsbereich unabhängig von der Eiweißkonzentration sein könnte. Es wurde deshalb eine wäßrige Kreatininlösung $(88 \mu \mathrm{mol} / \mathrm{l})$ ohne Albumin und mit steigendem Albumingehalt analysiert (Tab. 4).

Aus Tabelle 4 geht eindeutig hervor, daß bei unserer Methode eine Störung durch Eiweiß auszuschließen ist, im Gegensatz zu einem kürzlich veröffentlichten Verfahren (10), dessen Grundlage die unterschiedliche pH-Abhängigkeit der JAFFÉ-Reaktion von Kreatinin und Nichtkreatinin-Chromogenen ist.

\section{Methodenvergleich}

93 Seren wurden mit der hier beschriebenen Methode sowie mit dem Fullererde-Verfahren mit Enteiweißen (18) analysiert. Der Kreatiningehalt der Proben variierte dabei von 36 bis $1380 \mu \mathrm{mol} / 1$.

In Abbildung 2 sind die Ergebnisse der beiden Methoden graphisch gegeneinander aufgetragen. Der Korrelationskoeffizient beträgt $\mathbf{r}=0,998$, die Gleichung der Regressionsgeraden lautet:

$$
y=1,24+0,995 x \text {. }
$$

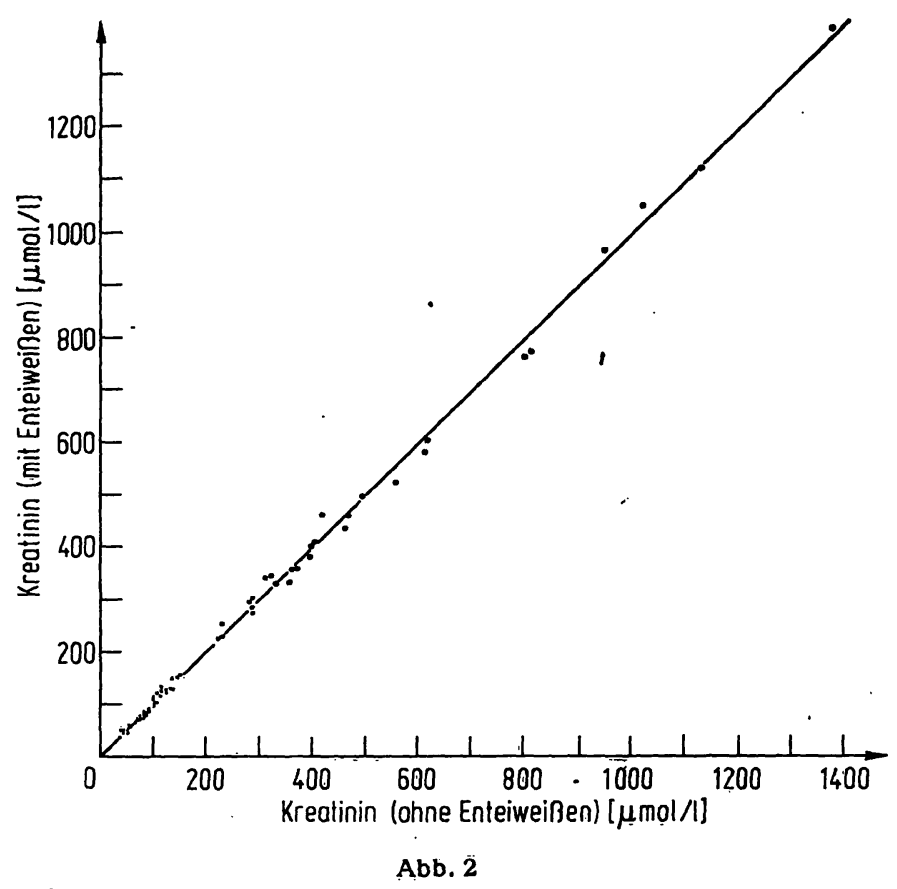

Meßwerte der beiden Methoden mit eingezeichneter Regressionsgeraden

$\mathrm{Da}$ der Achsenabschnitt der Regressionsgeraden nicht signifikant von 0 und der Regressionskoeffizient nicht signifikant von 1 verschieden ist, können für die hier beschriebene Methode der Kreatininbestimmung im Serum die von uns schon früher (18) publizierten Normalwerte übernommen werden:

Männer: $56,6-92,2 \mu \mathrm{mol} / 1, \quad$ Median: $72,6 \mu \mathrm{mol} / 1$

Frauen: $\quad 49,6-80,5 \mu \mathrm{mol} / 1$, Median: $60,2 \mu \mathrm{mol} / 1$

Gesamt: $\quad 50,4-92,2 \mu \mathrm{mol} / 1, \quad$ Median: $65,5 \mu \mathrm{mol} / 1$.

\section{Literatur}

1. Beyermand, K. (1967), Clin. Chim. Acta 17, 47-52. - 2. BeyermanN, K., GeroK, W. \& Groth, U. (1967), Klin. Wochenschr. 45, 950-953. - 3. Bartels, H. \& BöHMER, M. (1971), Clin. Chim. Acta 32, 81-85. - 4. Bartels, H., Böhmer, M. \& Heierdi, C. (1972), Clin. Chim. Acta 37, 193-197. - 5. Cook, J. G. H. (1971), Clin. Chim. Acta 32, 485-486. - 6. Fabiny, D. L. \& Ertingshausen, G. (1971), Clin. Chem. 17, 696-700. 7. Larsen, K. (1972), Clin. Chim. Acta 38, 475-476. - 8. LarSEN, K. (1972), Clin. Chim. Acta 41, 209-217. - 9. ZeNDER, R. \& JACOT, P. (1972), Anal. Letters 5, 143-152. - 10. RaABO, E. \& Wallöe-Hansen, P. (1972), Scand. J. Clin. Lab. Invest. 29, 297-301. - 11. Stoten, A. (1968), J. Med. Lab. Technol.
25, 240-247. - 12. Rockerbie, R. A. \& RASMUSSEN, K. L. (1967), Clin. Chim. Acta 15, 475-479. - 13. Teger-Nilsson, A.-C. (1961), Scand. J. Clin. Lab. Inviest. 13, 326-331. - 14. Mrtchell, R. J. (1973), Clin. Chem. 19, 408-410. - 15. Borsook, H. (1935), J. Biol. Chem. 110, 481-493. - 16. OWEN, J. A. IGGO, B., SCANDRETT, F. J. \& STEWART, C. P. (1954), Biochem. J. 58, 426-437. - 17. LøKen, F. (1954), Scand. J. Clin. Lab. Invest. 6, 325-334. - 18. KNoll, E. \& Stamm, D. (1970), diese Z. 8, 582-587. - 19. GorTER, E. \& DE GRAAF, W. C. (1955), Klinische Diagnostiek (LUBSEN, N., BECKER, J. H. \& DE VRIEs, L. A., Hrsg.) 7. Aufl., S. 278-281, H. E. Stenfert Kroese N. V. Leiden.
Dr. E. Knoll

Priv. Doz. Dr. Dr. H. Wisser Abteilung für Klinische Chemie Robert-Bosch-Krankenhaus 7 Stuttgart 50 Auerbachstraße 110 